\title{
Credit risk and Basel II: Are non-profit firms financially different?
}

Barbara Luppi*, Massimiliano Marzo ${ }^{\dagger}$, Antonello E. Scorcu ${ }^{\ddagger}$

\begin{abstract}
We estimate a model of credit risk for portfolios of Small and Medium-sized enterprises, conditional on being a non-profit or for-profit firms. The estimation is based on a unique dataset on Italian firms provided by a large commercial bank. We show that the main variables to identify creditworthiness are different for non-profit and for-profit firms. Traditional balance sheet information seems to be less crucial for non-profit firms.
\end{abstract}

JEL Classification: G21, G28

Key words: SME finance; Basel II; Retail banking; Non-profit

\footnotetext{
* Corresponding author: CEFIN and Dipartimento di Economia Politica, Viale Berengario, 22, 44100 Modena. Email address: barbara.luppi@unimore.it

$\dagger$ Dipartimento di Scienze Economiche, Piazza Scaravilli, 240126 Bologna. Email address: massimiliano.marzo@unibo.it

$\$$ RCEA and Dipartimento di Scienze Economiche, Strada Maggiore, 4540125 Bologna. Email address: antonello.scorcu@,unibo.it
} 


\section{Introduction}

The New Basel Capital Accord, known as Basel II, introduces capital requirement rules for banks depending on the borrower's riskiness. Credit ratings will play a crucial role in the future, as shown in Czarnitzki et all. (2007). Each borrower receives a credit score on the basis of bank's internal credit risk rating system, designed to assess creditworthiness on the basis of objective criteria.

Basel II makes more urgent the need to establish a sound method to estimate the probability of default (PD), providing both good prediction and explicative capabilities. However, a great heterogeneity characterizes credit risk modelling and no standard and robust model emerges. It is therefore important to assess the role of firm's specific characteristics in determining credit risk.

The present work investigates whether non-profit firms differ from for-profit firms in terms of firm's characteristics that play the most significant role in the prediction of PD. Credit risk models for non-profit and for-profit firms might not coincide. It is often claimed that non-profit firms aim at maximising social value and have therefore a different objective function with respect to for-profit organizations. Some of the standard measures of economic performance might not be relevant in the evaluation of non-profit organizations. A standard credit risk model therefore might not capture these specific characteristics and might not assess adequately PD, probably inducing inefficient rationing on the credit market for non-profit firms.

Moreover, since 2002 Italian non-profit firms are allowed to issue financial bonds on capital markets ${ }^{i}$, the possibility to raise funds on capital markets in plain competition with for profit firms makes the evaluation of riskiness of non profit organizations even more important, given their peculiar characteristics and operating methods.

The structure of the rest of the note is as follows. In section II the methodology is discussed, in section III the data are described. In section IV we present and discuss our results. Conclusions are presented in Section V.

\section{II: Model and Methodology}

We estimate credit risk models specific for a retail portfolio of loans granted to non-profit Small and Medium enterprises (SME), and for- profit SMEs.

From a methodological perspective, according to the nature of data available and methodological results as in Crouchy, Galai and Mark (2001), a logit regression is applied to the population of firm, conditioning on firm's type. For each firm in the sample, indexed $i=1, \ldots n$, the

values of a binary response variable $\mathrm{Y}_{\mathrm{i}}$ and a vector of $\mathrm{K}$ covariates $x_{i}=\left(x_{i 1}, x_{i 2}, \ldots, x_{i K}\right)$ are assumed to be known. In the logit framework, the response variable is distributed according to a Bernoulli distribution:

$$
p\left(x_{i}\right)=\operatorname{Pr}\left(Y_{i}=1 \mid X=x_{i}\right)=\frac{\exp \left(x_{i}^{\prime} \beta\right)}{1+\exp \left(x_{i}^{\prime} \beta\right)_{i}}
$$

where $p\left(Y_{i}=1\right)$ denotes the PD of firm i, and the logit regression coincide with the linear predictor:

$$
\ln \left(\frac{p\left(x_{i}\right)}{1-p\left(x_{i}\right)}\right)=x_{i}^{\prime} \beta=\beta_{0}+\beta_{1} x_{i 1}+\ldots+\beta_{K} x_{i K}
$$

where $\beta_{0}$ represents the overall intercept and $\beta=\left(\beta_{1}, \ldots \beta_{K}\right)$ a vector of $\mathrm{K}$ regression coefficients.

The estimation procedure relies both on firm's quantitative and qualitative information. For each firm type we implement a stepwise variable selection process, based on a likelihood-ratio test with significance level set at 5\%.

We perform a series of robustness tests. Restricted versions of the model are estimated conditional on being a for-profit or a non-profit firm. Three alternative restricted models are estimated including only a subset of explanatory variables: economic performance ratios, liquidity 
measures and debt structure proxies. We perform likelihood ratio tests on restricted models and we always reject the null hypothesis that the omitted variables in the general model have no impact on PDs. Moreover we reject the hypothesis that models for for-profit and non-profit firms are not significantly different.

The estimated model is robust to alternative specifications (explanatory variables in levels, instead of ratios and probit specification). We check for heteroskedasticity in errors in the probit estimation, with heteroskedastic variance in the form

$$
\operatorname{Var}(\varepsilon)=\exp \left(\gamma^{\prime} z\right)
$$

where $\mathrm{z}$ indicates the vector of variables included in the variance specification. We perform the variance heteroskedasticity test under different specifications of $\mathrm{z}$, including all explanatory variables and subsets of them, measuring liquidity or economic performance.

\section{Data}

The analysis is based on a data base provided by a large Italian commercial bank. The sample consists of about 4,000 firms having annual sales of less than 10 million Euros in the period 2001-02, classified as Small and Medium enterprises according to Basel II. One eighth of the sample is represented by non-profit firms ${ }^{\mathrm{ii}}$.

The data set displays unique features ${ }^{\mathrm{iii}}$ with respect to all the other studies on Italian firms, as Fabi et al (2005), Bocchi-Lusignani (2004) and Quagliarello (2007). First, the data set is representative of a retail portfolio for a commercial bank; the sample is designed to replicate the distribution of exposures of the bank's overall retail portfolio geographically, by sector of activity and firm's size. The data base contains detailed information on firms, including financial variables coming from balance sheets and other firm specific variables. The dataset specifies variables regarding the quality of the customer-bank relationship, allowing to evaluate credit risk for retail portfolios, within the Basel II framework, using similar data available for the bank internal credit risk evaluation system.

However, the default with respect to Basel II definition includes not only loans classified as non performing, substandard and loans past due 90 days, but also delayed payments by the firm, as we observe even firms which are not up to date with payments of bank debts, but are not necessarily going bankrupt ${ }^{\mathrm{iv}}$. In the following we use the label "stress" instead of default.

Panel A of Table 1 shows the distribution of defaults across non-profit and for-profit firms and Panel B the summary statistics of variables used in the estimation, conditional on firm type.

\section{Results}

Table 2 presents the results of the estimation conditional on being either a non-profit or a for-profit firm.

Significant differences in the credit risk models emerge. Crucially standard measures of economic performances are not statistically significant in the prediction of PD of non-profit firms. EBIDTA/TA and ROI do not influence PDs for non-profit firms, while they are highly significant and negatively correlated with PDs in the case of for-profit SMEs. An analogous result is obtained for measures of liquidity as $\mathrm{CF} / \mathrm{TA}$ and for proxy of financial structure as SD/TD.

Only "structural" variables as S/TA and TD/TA have a significant impact on PDs for both non-profit and for-profit firms. The evidence indicates that non-profit firms do have peculiarities that are not captured by standard measures of economic performance. This implies that standard credit risk models that rely only on firm's profitability, liquidity and financial structure may imperfectly assess PD of a non-profit firm, incurring in the risk of credit rationing. We perform an out-of sample prediction of the model estimated for for-profit firms on the sample of non-profit firms. The model performance in terms of correct classification of sound and unsound firms is reduced by more than $10 \%$, determining a higher average PD for non-profit firms. 
The firm sector of activity and regional location affect differently PD estimates conditional on juridical structure. Non-profit firms in northern and central Italy are less risky than the ones located in the South. From an historical perspective, the cooperative movement is more deeply rooted in north-central Italy and seems to have a competitive advantage in terms of higher financial stability $^{\mathrm{v}}$. On the contrary, for-profit firms located in northern Italy are riskier. Only firms operating in transportation sector are riskier independently of juridical structure, while service sector is riskier for non-profit firms and manufacture in case of for-profit SMEs.

The credit risk models for non-profit and for-profit firms share some common features. PDs are inversely correlated with firm's size, measured in terms of number of workers (NW) and sale volume (S/TA) ${ }^{\mathrm{vi}}$, confirming Basel II's assumptions.

The dataset includes also a proxy of the quality of the firm-bank relationship, indicating whether the bank does not register any problem in the lending relationship in the year under scrutiny. The variable plays an important role in PD estimation: the better the quality of the relationship between the bank and a specific firm, the lower is firm's PD, especially in quantitative terms for non-profit firms.

An overall performance of the credit risk model is given by the accuracy ratio, equal to $83.89 \%$ for for-profit firms and $97.74 \%$ for non-profit firms - which is good compared to other studies on Italian firms where it ranges between 50 and $70 \%$.

\section{Conclusions}

We provide a comparative analysis of credit risk associated with loans granted either to nonprofit or for-profit SMEs. Within the framework of Basel II, we provide striking evidence of the need to tailor the credit risk model in order to capture specific features of firms constituting bank's retail portfolio. Contrary to evidence for for-profit firms, non-profit firms present special features such that standard measures of profitability, liquidity and debt structure do not play any role in predicting PDs. This suggests also the opportunity to develop models able to capture at best the specific features of this group of firms.

We find also common effects on PDs for non-profit and for-profit firms in terms of structural variables, sales, total debts. Additionally, size matters also within the retail segment. 


\section{References}

Bocchi, L., and G. Lusignani (2004) Le nuove Regole di Basilea 2: prime valutazioni di impatto sul Rapporto Banca-Impresa in Italia, Banca, Impresa, Società vol. XXIII (2), 209--237.

Cannata, F., F. Fabi, and S. Laviola, (2002) Rating interni e gestione del rischio di credito: la misurazione delle probabilità di insolvenza, Bancaria, 4, 45--62

Crouchy, M., D. Galai and R. Mark (2001) A Comparative Analysis of Current Credit Risk Models, Journal of Banking and Finance, 24, 59--117

Czarnitzki, D. and K. Kraft (2007) Are Credit Ratings valuable information?, Applied Financial Economics, forthcoming.

Fabi, F., S. Laviola and P. Marullo Reedtz, (2005) The New Basel Capital Accord and banks' lending decisions, Journal of Financial Stability, 1, 501--521

Laitinen, E. K. (1999) Predicting a corporate credit analyst's risk estimate by logistic and linear models, International Review of Financial Analysis, 8(2), 97--121

Luppi, B., M. Marzo, A. E. Scorcu (2006) A credit risk model for Italian SMEs, mimeo.

Quagliarello, M. (2007), Bank's riskiness over the business cycle: a panel analysis on Italian intermediaries, Applied Financial Economics, 17(2), 119--138

Saurina, J., and C. Trucharte, (2004) The Impact of Basel II on Lending to Small-and-MediumSized Firms: A Regulatory Policy Assessment Based on Spanish Credit Register Data, Journal of Finance Services Research, 26, 121-144 
Table 1. Data

Panel A: Structure of the sample

\begin{tabular}{c|ccc}
\hline $\begin{array}{l}\text { Dependent } \\
\text { variable: stress }\end{array}$ & Non-profit & For-profit & Total \\
\hline 0 & & & 3,558 \\
1 & 271 & 2,287 & 336 \\
\hline Total & 18 & 318 & 3894 \\
\hline
\end{tabular}

Panel B: Summary statistics

\begin{tabular}{|lllllllll|}
\hline & \multicolumn{4}{c}{ Non-profit } & \multicolumn{5}{c|}{ For-profit } \\
\hline & Mean & $\begin{array}{l}\text { Standard } \\
\text { deviation }\end{array}$ & $\begin{array}{l}\text { Minimu } \\
\mathrm{m}\end{array}$ & $\begin{array}{l}\text { Maxim } \\
\text { um }\end{array}$ & Mean & $\begin{array}{l}\text { Standard } \\
\text { Deviation }\end{array}$ & Min & Max \\
\hline BFR & 1.7855 & 0.4112 & 0 & 2 & 1.7587 & 0.4279 & 0 & 2 \\
\hline AGE & 2.4049 & 1.2299 & 1 & 5 & 2.6175 & 1.2462 & 1 & 5 \\
\hline NW & 1.1419 & 0.5809 & 1 & 4 & 1.085 & 0.4306 & 1 & 4 \\
\hline SD/TD & 0.79 & 0.2261 & 0.0125 & 1 & 0.8151 & 0.2031 & 0 & 1 \\
\hline TD/TA & 0.9571 & 0.8358 & 0.0702 & 9.8524 & 0.903 & 0.6047 & 0 & 7.3333 \\
\hline NSF/ TA & -0.0018 & 0.0933 & -4.3634 & 0.875 & 0.0033 & 0.370 & -13.9565 & 3.5806 \\
\hline NSF_P & 0.0316 & 0.1749 & 0 & 1 & 0.4528 & 0.4978 & 0 & 1 \\
\hline CF/TA & -.0209 & 0.6393 & -9.2 & 0.6154 & 0.031 & 0.3563 & -13.9565 & 3.8548 \\
\hline S/TA & 0.2221 & 1.4640 & 0 & 46.153 & 1.9168 & 2.2406 & 0 & 62.5 \\
\hline XS & 0.0239 & 0.1527 & 0 & 1 & 0.2313 & 0.4217 & 0 & 1 \\
\hline S & 0.0149 & 0.1211 & 0 & 1 & 0.1740 & 0.3792 & 0 & 1 \\
\hline EBIDTA/ & -0.024 & 0.3422 & -4.3634 & 0.875 & 0.0887 & 0.4038 & -13.587 & 6.1396 \\
TA & & & & & & & & \\
\hline ROI & -0.154 & 0.2150 & -91.54 & 50.75 & -0.123 & 0.2567 & -45.16 & 48.15 \\
\hline
\end{tabular}

BFR is 0 if no quality lending relationship, 1 if high quality for one year and 2 for at least two years.

AGE: firm's months of activity (5 classes: $<23$ months; 24-71; 72-143;144-288; >288).

NW: firm's workers (4 classes: 0-3 workers; 4-10;11-20; >20)

$\mathrm{SD} / \mathrm{TD}$ : short-term debt on total debt. TD/TA: total debt on total asset value.

NSF/TA: net self financing flow on TA. CF/TA: cash flows on TA. S/TA: annual sale volume on TA. XS and S are dummies with value 1 in case of firm's annual sale respectively less than 250.000 and 500,000 euro.

EBIDTA/TA is EBIDTA on TA.

North and South are regional dummies. Transport, Service and Manufacture are sectorial dummies. 
Table 2. Logit estimation results

\begin{tabular}{|c|c|c|c|c|}
\hline \multirow[t]{2}{*}{ Dependent variable: stress } & \multicolumn{2}{|c|}{ Non-profit } & \multicolumn{2}{|c|}{ For-profit } \\
\hline & $\begin{array}{l}\text { Coefficient } \\
\text { (standard } \\
\text { error) }\end{array}$ & $\begin{array}{c}\text { Elasticity } \\
\text { (standard error) }\end{array}$ & $\begin{array}{l}\text { Coefficient } \\
\text { (standard } \\
\text { error) }\end{array}$ & $\begin{array}{l}\text { Elasticity } \\
\text { (standard } \\
\text { error) }\end{array}$ \\
\hline \multirow[t]{2}{*}{ BFR } & $-4.474 * * *$ & -7.988 & $-2.379 * * *$ & -4.001 \\
\hline & $(1.349)$ & $(2.410)$ & $(0.141)$ & $(0.248)$ \\
\hline \multirow[t]{2}{*}{ AGE } & $0.607^{*}$ & 1.460 & $0.458 * * *$ & 1.138 \\
\hline & $(0.391)$ & $(0.940)$ & $(0.057)$ & $(0.143)$ \\
\hline NW & $-1.427 *$ & 1.630 & $-0.479 * * *$ & -0.502 \\
\hline \multirow{2}{*}{$\mathrm{SD} / \mathrm{TD}$} & $-3344 *$ & -2641 & $165 * * *$ & 0891 \\
\hline & $(2.057)$ & $(1.625)$ & $(0.363)$ & $(0.283)$ \\
\hline \multirow[t]{2}{*}{ TD/TA } & $5.463 * * *$ & 5.228 & $0.357 * * *$ & 0.298 \\
\hline & (1.553) & (1.487) & $(0.104)$ & $(0.088)$ \\
\hline \multirow[t]{2}{*}{ NSF/ TA } & $8.929 * * *$ & -0.218 & $1.304 * * *$ & 0.004 \\
\hline & $(3.355)$ & $(0.082)$ & $(0.359)$ & $(0.001)$ \\
\hline NSF_P & $\begin{array}{c}-4.072 * * * \\
(1.674)\end{array}$ & $\begin{array}{r}-1.733 \\
(0.712)\end{array}$ & $\begin{array}{c}-0.344 * * * \\
(0.144)\end{array}$ & $\begin{array}{l}-0.168 \\
(0.067)\end{array}$ \\
\hline \multirow{2}{*}{ CF/TA } & -0.134 & 0.003 & $-0.883 * *$ & -0.027 \\
\hline & $(0.634)$ & $(-0.013)$ & $(0.405)$ & $(0.012)$ \\
\hline \multirow[t]{2}{*}{$\mathrm{S} / \mathrm{TA}$} & $-1.597 * * *$ & -4.782 & $-0.178 * * *$ & -0.354 \\
\hline & $(0.491)$ & (1.471) & $(0.047)$ & $(0.092)$ \\
\hline \multirow[t]{2}{*}{ XS } & $4.022 * * *$ & 1.049 & 0.011 & -0.008 \\
\hline & (1.494) & $(0.362)$ & $(0.171)$ & $(0.041)$ \\
\hline \multirow[t]{2}{*}{ S } & $5.226 * * *$ & -0.03 & 0.097 & -0.015 \\
\hline & (1.804) & $(0.674)$ & $(0.179)$ & $(0.032)$ \\
\hline \multirow[t]{2}{*}{ EBITDA/ TA } & -0.279 & -0.004 & $-0.439 * *$ & -0.035 \\
\hline & $(1.731)$ & $(0.028)$ & $(0.218)$ & $(0.018)$ \\
\hline ROI & $\begin{array}{c}-0.00005 \\
(0.001)\end{array}$ & $\begin{array}{r}-0.716 \\
(0.309)\end{array}$ & $\begin{array}{c}-0.001 * * * \\
(0.0002)\end{array}$ & $\begin{array}{r}-0.305 \\
(0.119)\end{array}$ \\
\hline \multirow[t]{2}{*}{ North } & $-2.687 * *$ & 0.716 & -0.191 & -0.054 \\
\hline & $(1.162)$ & $(0.309)$ & $(0.152)$ & $(0.043)$ \\
\hline South & $\begin{array}{r}4.950 * * * \\
(1.614)\end{array}$ & $\begin{array}{l}0.704 \\
(0.229)\end{array}$ & $\begin{array}{l}-0.024 \\
(0.203)\end{array}$ & $\begin{array}{r}-0.017 \\
(0.024)\end{array}$ \\
\hline Transport & $\begin{array}{c}7.810 * * \\
(2.331)\end{array}$ & $\begin{array}{l}0.919 \\
(0.274)\end{array}$ & $\begin{array}{c}0.224 * * \\
(0.287)\end{array}$ & $\begin{array}{l}0.013 \\
(0.013)\end{array}$ \\
\hline Services & $\begin{array}{c}2.697 * * * \\
(1.355)\end{array}$ & $\begin{array}{l}1.185 \\
(0.596)\end{array}$ & $\begin{array}{r}-.0136 \\
(0.198)\end{array}$ & $\begin{array}{r}-0.003 \\
(0.041)\end{array}$ \\
\hline Manufacture & $2.084 * * *$ & 0.274 & $0.488 * * *$ & 0.135 \\
\hline Constant & $\begin{array}{c}-6.497 * * \\
(3.298)\end{array}$ & & $\begin{array}{c}-0.022 * * \\
(0.507)\end{array}$ & \\
\hline Log-likelihood & -26 & & -808 & \\
\hline Pseudo $\mathrm{R}^{2}$ & & & 24. & \\
\hline Number of observations & & & & \\
\hline Area under ROC & & & 83. & \\
\hline
\end{tabular}

Notes:

$* * *$ indicates significance at $1 \%$ level,

$* *$ at $5 \%$

$*$ at $10 \%$. 
${ }^{\mathrm{i}}$ Bond issues by non-profit firms are allowed under conditions stated in Deliberazione of 3/5/1999 of CICR published in 8/7/1999.

ii We limit our attention to limited liability non-profit firms called "società cooperativa a responsabilità limitata" (SCRL).

iii Most of existing studies draw samples from national registers without direct reference to banks' portfolios.

iv Because of the default definition, estimated PD can be interpreted as an early warning to the bank in order to detect future situations of stress in loan repayments. There are no reasons to expect the existence of differences between nonprofit and for-profit firm w.r.t. this feature. See Luppi et all. (2006).

${ }^{v}$ A share of non distributed earnings of the non-profit firms is compulsory allocated as reserves.

${ }^{v i}$ Saurina and Trucharte (2004) provide similar evidence for Spanish economy. 